\title{
Numerical Simulation of the Influence of Width of a Prefabricated Crack on the Dimensionless Stress Intensity Factor of Notched Semi-Circular Bend Specimens
}

\author{
Sheng Zhang, ${ }^{1,2}$ Longfei Wang, ${ }^{1}$ and Mingzhong Gao ${ }^{3}{ }^{3}$ \\ ${ }^{1}$ School of Energy Science and Engineering, Henan Polytechnic University, Jiaozuo, Henan 454001, China \\ ${ }^{2}$ Collaborative Innovation Center of Coal Work Safety, Jiaozuo, Henan 454001, China \\ ${ }^{3}$ Institute of Deep Earth Sciences and Green Energy, College of Civil Engineering, Shenzhen University, Shenzhen 518060, China \\ Correspondence should be addressed to Mingzhong Gao; gmz1980@sohu.com
}

Received 12 November 2018; Revised 24 March 2019; Accepted 4 April 2019; Published 5 May 2019

Academic Editor: Salvatore Caddemi

Copyright (c) 2019 Sheng Zhang et al. This is an open access article distributed under the Creative Commons Attribution License, which permits unrestricted use, distribution, and reproduction in any medium, provided the original work is properly cited.

To analyze the effect of the width of a prefabricated crack on the dimensionless stress intensity factor of notched semi-circular bend (NSCB) specimens, ABAQUS software was employed to perform numerical calibration of the crack tip stress intensity factor for the width of prefabricated cracks in the range of $0.0 \sim 2.0 \mathrm{~mm}$. The relative errors of the dimensionless stress intensity factor for different widths of prefabricated cracks were analyzed. The results indicate that the dimensionless stress intensity factor shows an approximate linear increase as the width of the prefabricated crack increases. The longer is the length of the prefabricated crack, the "faster" is the increase in speed. The effect of the dimensionless support spacing on the increase in the speed of the dimensionless stress intensity factor due to the increase in crack width is minimal. When the prefabricated crack width is $2.0 \mathrm{~mm}$, the maximum relative error of the dimensionless stress intensity factor is $4.325 \%$. The new formula for the dimensionless stress intensity factor that eliminates the influence of the width of a prefabricated crack is given, which provides a theoretical basis for the more accurate fracture toughness value measured using an NSCB specimen.

\section{Introduction}

Rock mass is a typical noncontinuous natural medium, whose interior presents many defects, such as joints and cracks $[1,2]$. Because rock fractures cannot be simply determined by strength parameter measurement, the existence of internal cracks should be considered. Fracture toughness can characterize the ability of rock fissures to resist crack initiation and propagation [3-5]. Regarding the testing method, the International Society for Rock Mechanics (ISRM) has successively presented chevron notched short rod (SR) specimen, chevron notched three-point bend round bar (CB) specimen, cracked chevron notched Brazilian disc (CCNBD) specimen, and notched semi-circular bend (NSCB) specimen-a total of four types of specimens to test the mode I fracture toughness of rock [6-8]. Besides the four test configurations recommended by the ISRM, some scholars have proposed some specimens of other configurations to test the pure mode I, II, and III or mixed mode fracture toughness of rock materials. Such as diametrally compressed ring (DCR) specimen [9], cracked straight-through flattened Brazilian disk (CSTFBD) [10], edge cracked triangular (ECT) specimen [11], and edgenotched disc bend (ENDB) specimen [12-14]. The NSCB specimen is a new type of specimen employed in static fracture toughness tests, which was recommended by ISRM in 2014. This specimen was proposed by Chong and Kuruppu [15] and has been extensively employed in fracture toughness tests due to its simple structure, ease of specimen preparation, and loading [16-24]. However, in the calculation of fracture toughness by most researchers, the dimensionless stress intensity factor was obtained by substitution in the relevant formula recommended by the ISRM. In the process of deriving this formula, the recommended method applied ABAQUS software to establish a two-dimensional NSCB specimen model that contains line 
cracks (i.e., zero-width cracks) to calibrate the dimensionless stress intensity factor and then obtain a relevant calculation formula by fitting. During the preparation of a fracture toughness test specimen, which is affected by factors such as preparation methods, an artificial prefabricated crack has a certain width. Its crack tip is not ideally sharp but approximates the arc shape. The arc radius may substantially vary due to different processors, which causes a non-strict correspondence relation between the dimensionless stress intensity factor given by the recommended formula substitution and fracture load obtained by experiments. The obtained fracture toughness exhibits a certain deviation from the true fracture toughness value. Currently, the study which regards the influence of width of the prefabricated crack on the stress intensity factor is primarily focused on a disc-type specimen or three-point bending beams. Zhu and Wang [25] performed detailed experimental research and theoretical analysis of the relationship between the curvature radius of a rock specimen for three-point bending tests and the test value of fracture toughness. Dai and Wang [26] analyzed the influence of crack width on the dimensionless stress intensity factor of CCNBD specimens. Dong et al. [27] investigated the effect of crack form on the stress intensity factor of a cracked straight-through Brazilian disc (CSTBD). Zhang et al. [28] and Zhang and Liang [29] successively investigated the influence of the width of a prefabricated crack on the fracture toughness test of a holed-cracked flattened Brazilian disc (HCFBD) specimen. Zhou et al. [30] compared the fracture behavior and toughness of straight-notch disc specimens with those of central sharpnotch disc specimens. They discovered that the fracture toughness test values of straight-notch specimens were excessive, the crack usually initiated at the corner of the notch, and the test results were more scattered. Cui et al. [31] used a Hopkinson pressure bar to conduct dynamic impact tests of non-ideal crack disc specimens with center incisions. The test results showed that the ideal disc specimen can be replaced with a non-ideal crack disc specimen with a center incision when the width of the prefabricated crack is less than $1 \mathrm{~mm}$. Wang and Luo et al. [32-34] proposed a method that simultaneously determines the fracture toughness and tensile strength of rock using a series of U-shaped notched beams with the same notch depth and different root curvatures. The feasibility of this method was verified by both theoretical analysis and experimentation. Kolhe et al. [35] explored the influence of the crack tip radius on the fracture toughness of CB specimens. Barati and Alizadeh [36] performed research on the ratio of the notch tip curvature to the notch depth and its influence on the plane strain fracture toughness. Cicero et al. [37] examined the influence of the three-point bending beam notch radius on the dimensionless stress intensity factor and fracture toughness by the theory of critical distances (TCD) and explicated the influencing mechanism of the notch tip radius by scanning electron microscopy. Dehghany et al. [38] investigated the effects of the first non-singular stress terms on the fracture assessment of sharp V-notches under mixed mode loading. Hussain and Murthy [39] have proposed a simple, robust, and efficient point substitution type displacement based technique for finite element estimation of the notch stress intensity factors (NSIFs) of sharp V-notched configurations. The technique can acquire accurate NSIFs even in course meshes made of quadratic elements without the use of any special singular elements at the notch tip.

Currently, the influence of the width of a prefabricated crack on the dimensionless stress intensity factor of the NSCB specimen has not been reported. Analysis of the extent to which the width of the prefabricated crack influences the dimensionless stress intensity factor is necessary to improve the method that measures the fracture toughness of NSCB specimens.

For this reason, the dimensionless stress intensity factor of the crack tip was calibrated by ABAQUS software for different widths of the prefabricated cracks of the NSCB specimens in this paper. The influence of the width of a prefabricated crack on the dimensionless stress intensity factor is examined; the relative error of the dimensionless stress intensity factor for different widths of the prefabricated cracks is analyzed; and the corrected formula of the NSCB dimensionless stress intensity factor that eliminates the effect of crack width is obtained. It is worth pointing out that it is not easy to prefabricate a crack on rock, and the crack tip of the manually prepared specimen is not an ideal sharp type, but a U-shaped crack with a certain radian. Therefore, the next numerical research work in this paper is to treat the prefabricated crack into a U-shaped crack, which is consistent with the actual crack form in the specimen used by researchers to test rock fracture toughness.

\section{Calibration of Dimensionless Stress Intensity Factor}

2.1. Fracture Toughness Principle of NSCB Specimen. Figure 1 shows the loading of an NSCB specimen. The specimen in Figure 1 carries the concentrated load $P$; its radius is $R$; its disc thickness is $B$; the length and width of the artificially prefabricated crack are $a$ and $2 b$, respectively; and the support spacing is $S$. Considering the influence of the width of a prefabricated crack, the calculation of the mode I stress intensity factor is shown as follows:

$$
K_{\mathrm{I}}=\frac{P \sqrt{\pi a}}{2 R B} Y\left(\alpha_{0}, \alpha_{2 b}, \alpha_{\mathrm{t}}, \alpha_{\mathrm{S}}\right),
$$

where $P$ is the concentrated load, $\alpha_{0}=a / R$ is the dimensionless length of the prefabricated crack, $\alpha_{2 b}=2 b / R$ is the dimensionless width of the prefabricated crack, $\alpha_{\mathrm{t}}=B / R$ is the dimensionless specimen thickness, and $\alpha_{\mathrm{S}}=S / 2 R$ is the dimensionless support spacing. The dimensionless stress intensity factor value $Y\left(\alpha_{0}, \alpha_{2 b}, \alpha_{\mathrm{t}}, \alpha_{\mathrm{S}}\right)$ that is associated with length, width, and thickness of the prefabricated crack and the support spacing of the specimen is calculated by the following formula:

$$
Y\left(\alpha_{0}, \alpha_{2 b}, \alpha_{\mathrm{t}}, \alpha_{\mathrm{S}}\right)=\frac{2 K_{\mathrm{I}} R B}{P \sqrt{\pi a}} .
$$

2.2. Verification of Calibration Accuracy. To verify the accuracy of the equivalent regional integration method with respect to the stress intensity factor calibration in this paper, 


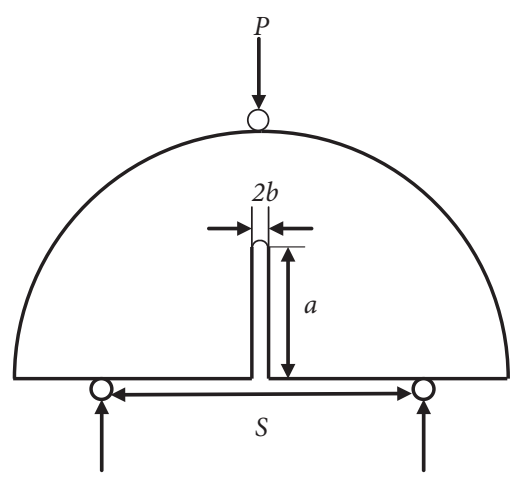

(a)

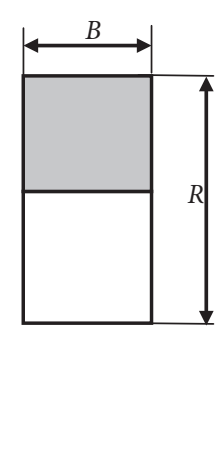

(b)

FIGURE 1: Loading diagram of the NSCB specimen: (a) plane diagram and (b) cross-sectional diagram.

the geometric parameters that were employed in the method suggested by the ISRM were selected. In the case of the dimensionless support spacing $\alpha_{\mathrm{S}}=0.5$, the stress intensity factors of the specimens were individually calibrated for different dimensionless crack lengths $\alpha_{0}=0.1,0.2,0.3,0.4$, $0.5,0.6,0.7$, and 0.8 . The calibrated result is compared with that derived from the internationally recommended formula (formula (3)); the result is shown in Figure 2.

$$
\begin{aligned}
Y= & -1.297+9.516 \alpha_{\mathrm{S}}-\left(0.47+16.457 \alpha_{\mathrm{S}}\right) \alpha_{0} \\
& +\left(1.071+34.401 \alpha_{\mathrm{S}}\right) \alpha_{0}^{2} .
\end{aligned}
$$

Figure 2 reveals that the calibrated result obtained by the equivalent region integration method of this paper is similar to that derived from the internationally recommended method formula (formula (3)). When the dimensionless support spacing is 0.5 and the crack length is 0.8 , the maximum error is $4.4 \%$. However, when the dimensionless crack length ranges from 0.4 to 0.6 , the maximum relative error of dimensionless stress intensity factor is $0.62 \%$. Within this range, the numerical calibration method adopted in this paper has good accuracy. Therefore, the dimensionless crack length studied in this paper ranges from 0.4 to 0.6 .

\section{Finite Element Analysis}

3.1. NSCB-Related Parameters. According to the range of support spacing and crack length given by the internationally recommended method, the dimensionless stress intensity factor with the common width of a prefabricated crack $(0.0 \sim 2.0 \mathrm{~mm})$ is calibrated for the NSCB specimens. The geometric and mechanical parameters of the specimens are shown in Table 1 . The material parameters used in the numerical model in this paper are based on the real material parameters of the limestone from Jiaozuo City, Henan Province, China. The geometrical parameter range covers the geometrical dimensions of NSCB specimens used in most cases for testing fracture toughness.

3.2. NSCB Specimen Finite Element Model. The NSCB specimens with prefabricated crack widths of $0.0 \sim 2.0 \mathrm{~mm}$,

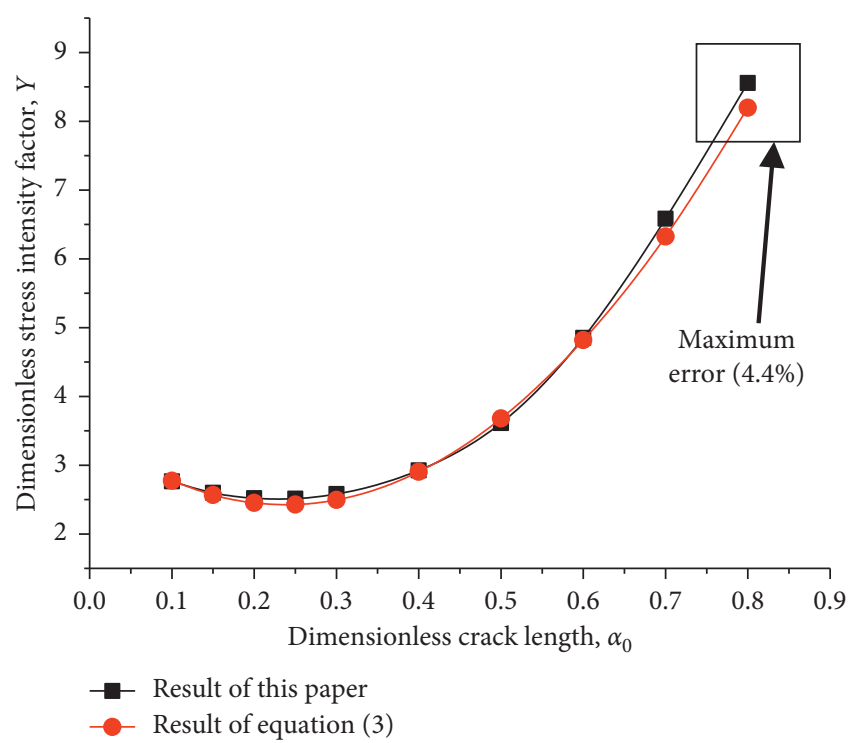

FIGURE 2: Comparison between calibration result of this paper and that obtained by formula (3).

dimensionless lengths of the prefabricated cracks of $0.4 \sim 0.6$, and a dimensionless support spacing of $0.5 \sim 0.8$ were analyzed using ABAQUS finite element software. The NSCB specimen loading is shown in Figure 1; the finite element model is shown in Figure 3.

Since the degree of the density of the mesh near the tip of the prefabricated crack will have a substantial influence on the calibration result of the dimensionless stress intensity factor, the prefabricated crack tip for different widths in Figure 3 is arranged using a local seeding technique to place seeds with the same meshing density, as shown in Figure 4(b). Considering the singularity of the crack tip, the 6-node triangular plane stress element (CPS6) is selected for the element in the crack tip integral region, and the 8-node quadrilateral element (CPS8) is selected for the grid element outside the crack tip integral region. The meshing technique uses a combination of free and sweeping meshing techniques. In terms of the boundary conditions, a load is applied to the top of the semidisc specimen, and a vertical upward constraint is applied to the left and right sides of the bottom of the semidisc with a centrally symmetric position. 
TABLE 1: NSCB specimen parameters.

\begin{tabular}{lccccc}
\hline $\begin{array}{l}\text { Elastic } \\
\text { modulus, } \\
E(\mathrm{GPa})\end{array}$ & $\begin{array}{c}\text { Poisson's } \\
\text { ratio, } \mu\end{array}$ & $\begin{array}{c}\text { Dimensionless } \\
\text { crack length, } \alpha_{0}\end{array}$ & $\begin{array}{c}\text { Specimen thickness } \\
\text { to diameter ratio, } \alpha_{\mathrm{t}}\end{array}$ & $\begin{array}{c}\text { Crack width, } \\
2 b(\mathrm{~mm})\end{array}$ & $\begin{array}{c}\text { Dimensionless } \\
\text { support spacing, } \alpha_{\mathrm{S}}\end{array}$ \\
\hline 63.94 & 0.27 & $0.4,0.5$, and 0.6 & 0.4 & $0.0,0.2,0.4,0.6,0.8,1.0,1.2,1.4,1.6,1.8$, and 2.0 & $0.5,0.6,0.7$, and 0.8 \\
\hline
\end{tabular}

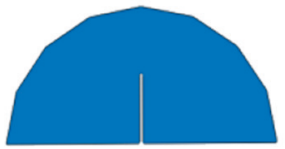

$2 b=0.2 \mathrm{~mm}$

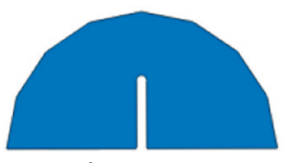

$2 b=1.2 \mathrm{~mm}$

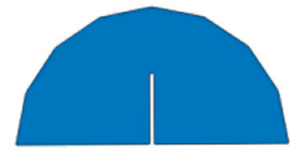

$2 b=0.4 \mathrm{~mm}$

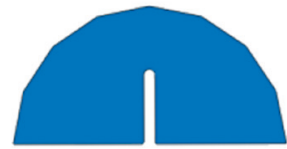

$2 b=1.4 \mathrm{~mm}$

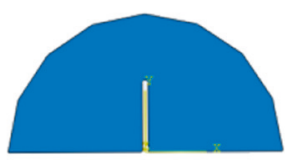

$2 b=0.6 \mathrm{~mm}$

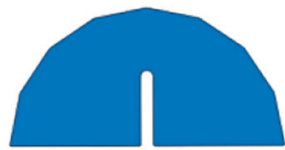

$2 b=1.6 \mathrm{~mm}$

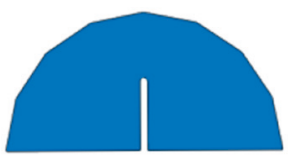

$2 b=0.8 \mathrm{~mm}$

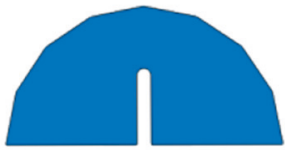

$2 b=1.8 \mathrm{~mm}$

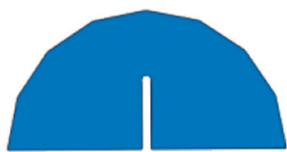

$2 b=1.0 \mathrm{~mm}$

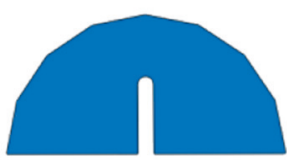

$2 b=2.0 \mathrm{~mm}$

FigURE 3: NSCB models with different widths of the prefabricated cracks.

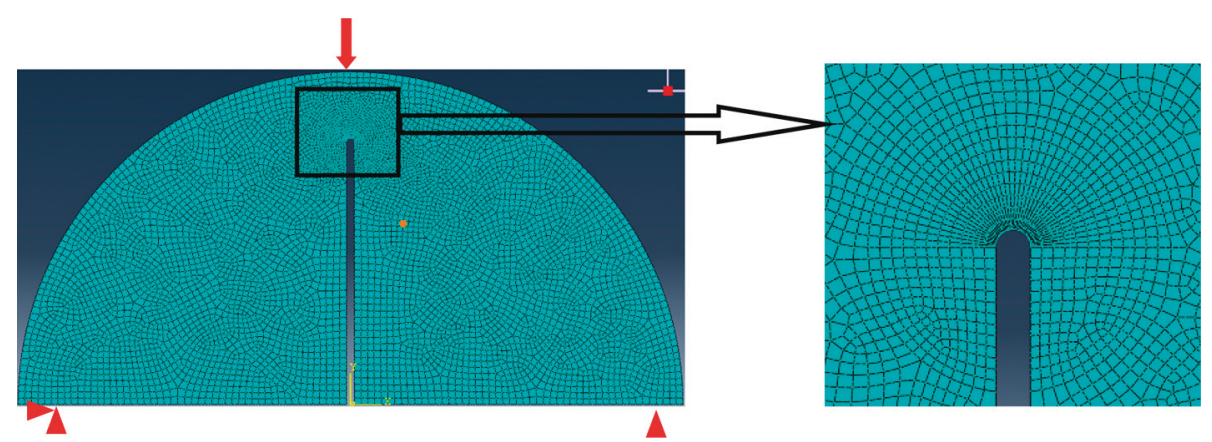

(a)

(b)

Figure 4: (a) NSCB specimen meshing. (b) Zoomed view of the mesh of the crack tip.

3.3. Calibration Results and Pattern Analysis of the Dimensionless Stress Intensity Factor. Based on the equivalent region integration method, the J-integral at the crack tip is obtained by ABAQUS software, and the stress intensity factor of the mode I crack is calculated by the following formula:

$$
K_{\mathrm{I}}=\sqrt{J E} \text {, }
$$

where $E$ is the elastic modulus. Substituting formula (4) into formula (2), the dimensionless stress intensity factor of the crack tip of the NSCB specimen with different crack widths is obtained for different support spacings and lengths of prefabricated cracks. The following calibration results are shown in Figure 5.

(1) In the case of a fixed support spacing and crack length, when the influence of crack width is considered (i.e., $2 b>0 \mathrm{~mm}$ ), the calibration value of the dimensionless stress intensity factor is larger than that of the ideal crack (i.e., $2 b=0 \mathrm{~mm}$ ). With an increase in the width of the prefabricated crack, the dimensionless stress intensity factor continuously increases.

(2) When the support spacing is fixed, the length of the prefabricated crack is within the range $\alpha_{0}=0.4 \sim 0.6$; the dimensionless stress intensity factor of each width of the prefabricated crack increases with the length of the prefabricated crack; and the longer is the length, the "faster" is the increase in speed.

(3) When the length of the prefabricated crack is fixed, the dimensionless stress intensity factor of the NSCB specimen increases with an increase in the width of the prefabricated crack within the range of the support spacing $\alpha_{\mathrm{S}}=0.5 \sim 0.8$; it is almost independent of the support spacing.

3.4. Analysis of Error Induced by Ignoring the Width of the Prefabricated Crack. The relative error $\delta$ between a prefabricated crack of a certain width and the ideal crack is calculated by formula (5). Table 2 shows the relative error between the dimensionless stress intensity factor and the ideal crack for different support spacings and lengths of prefabricated cracks:

$$
\delta=\frac{Y_{2 b}-Y_{0}}{Y_{0}}
$$

Figure 6 shows the maximum relative error bar chart of the dimensionless stress intensity factor of the NSCB specimen for the condition that the width of the 


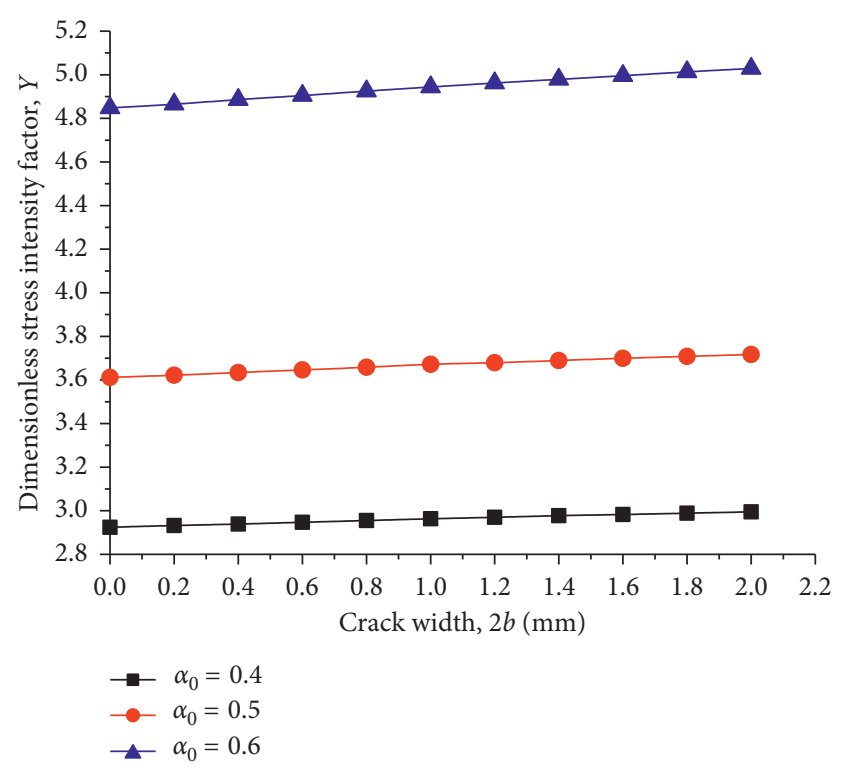

(a)

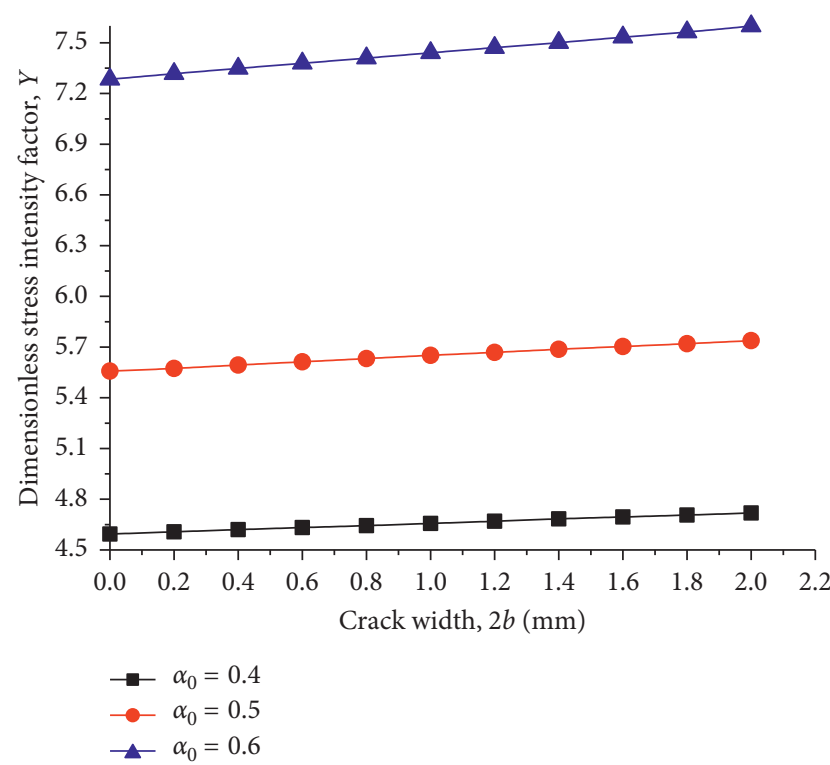

(c)

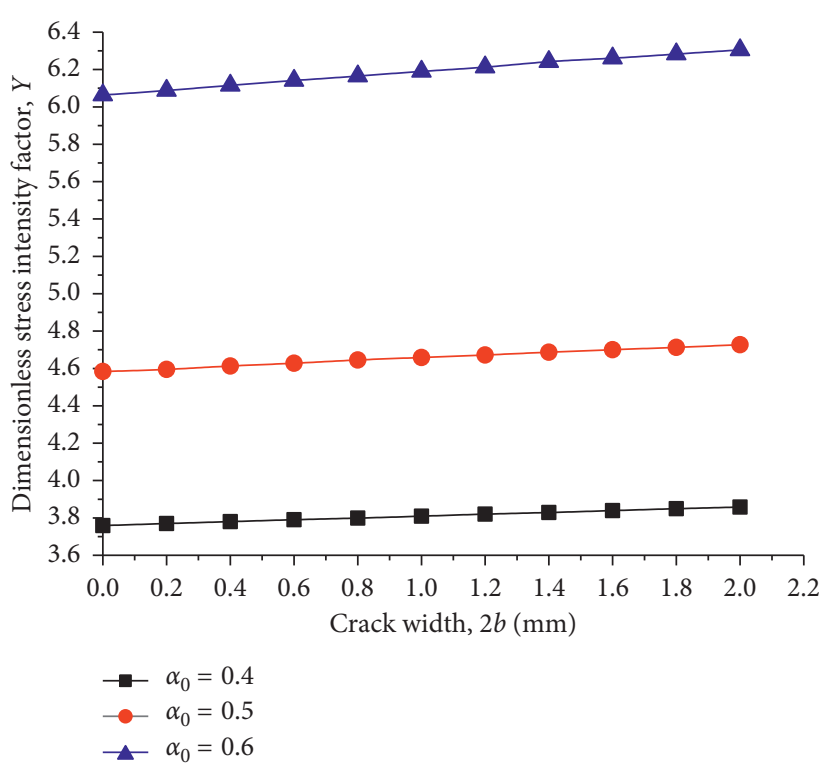

(b)

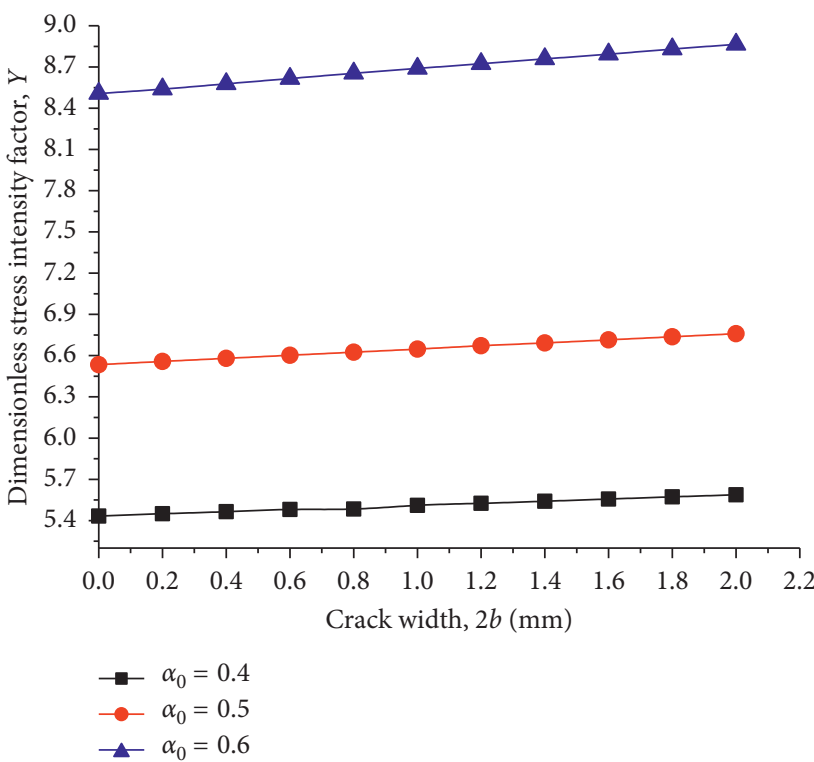

(d)

Figure 5: Dimensionless stress intensity factor variation diagram of NSCB specimens. (a) $\alpha_{\mathrm{S}}=0.5$, (b) $\alpha_{\mathrm{S}}=0.6$, (c) $\alpha_{\mathrm{S}}=0.7$, and (d) $\alpha_{\mathrm{S}}=0.8$.

prefabricated crack is fixed at $2.0 \mathrm{~mm}$, the dimensionless length of the prefabricated crack ranges from 0.4 to 0.6 , and the dimensionless support spacing ranges from 0.5 to 0.8 .

As shown in Figure 6, the increase in the width of the prefabricated crack significantly affects the dimensionless stress intensity factor of the NSCB specimen, which is simultaneously affected by the support spacing and crack length. The maximum relative error of the dimensionless stress intensity factor $(4.325 \%)$ is obtained at the support spacing of $\alpha_{\mathrm{S}}=0.7$ and crack length of $\alpha_{0}=0.6$. When the dimensionless support spacing is 0.5 and 0.8 , the relative error of the dimensionless stress intensity factor continuously increases with an increase in the length of the prefabricated crack. When the dimensionless support spacing is
0.6 and 0.7 , the change pattern does not monotonously increase.

3.5. Dimensionless Stress Intensity Factor Formula Eliminates the Influence of Width of the Prefabricated Crack. To obtain a more general situation, the crack width is non-dimensional to obtain a more general relationship between the dimensionless stress intensity factor and the dimensionless crack width. The three-dimensional scatter plot and the fitted surface are shown in Figure 7.

As shown in Figure 7, the scatter plot between the dimensionless stress intensity factor and the crack length and crack width is distributed in the vicinity of a curved surface 
TABLE 2: Errors of dimensionless stress intensity factors of the NSCB specimens due to different widths of prefabricated cracks.

\begin{tabular}{lcccccccccccc}
\hline \multirow{2}{*}{ Crack width, $2 b(\mathrm{~mm})$} & \multicolumn{3}{c}{$\alpha_{\mathrm{S}}=0.5$} & \multicolumn{3}{c}{$\alpha_{\mathrm{S}}=0.6$} & \multicolumn{3}{c}{$\alpha_{\mathrm{S}}=0.7$} & \multicolumn{2}{c}{$\alpha_{\mathrm{S}}=0.8$} \\
& 0.4 & 0.5 & 0.6 & 0.4 & 0.5 & 0.6 & 0.4 & 0.5 & 0.6 & 0.4 & 0.5 & 0.6 \\
\hline 0.0 & 0.000 & 0.000 & 0.000 & 0.000 & 0.000 & 0.000 & 0.000 & 0.000 & 0.000 & 0.000 & 0.000 & 0.000 \\
0.2 & 0.274 & 0.277 & 0.351 & 0.293 & 0.240 & 0.412 & 0.283 & 0.288 & 0.453 & 0.313 & 0.367 & 0.376 \\
0.4 & 0.513 & 0.609 & 0.784 & 0.559 & 0.633 & 0.858 & 0.566 & 0.648 & 0.879 & 0.589 & 0.704 & 0.823 \\
0.6 & 0.787 & 0.941 & 1.176 & 0.825 & 0.960 & 1.286 & 0.827 & 0.990 & 1.304 & 0.883 & 1.056 & 1.281 \\
0.8 & 1.060 & 1.274 & 1.588 & 1.064 & 1.331 & 1.682 & 1.088 & 1.331 & 1.716 & 0.939 & 1.393 & 1.728 \\
1.0 & 1.334 & 1.661 & 1.980 & 1.330 & 1.636 & 2.095 & 1.371 & 1.673 & 2.155 & 1.436 & 1.729 & 2.139 \\
1.2 & 1.573 & 1.855 & 2.351 & 1.623 & 1.920 & 2.474 & 1.654 & 1.997 & 2.567 & 1.712 & 2.112 & 2.551 \\
1.4 & 1.813 & 2.132 & 2.702 & 1.862 & 2.247 & 2.952 & 1.959 & 2.321 & 2.979 & 1.988 & 2.418 & 2.962 \\
1.6 & 2.018 & 2.409 & 3.053 & 2.128 & 2.531 & 3.266 & 2.199 & 2.609 & 3.418 & 2.264 & 2.770 & 3.362 \\
1.8 & 2.223 & 2.658 & 3.403 & 2.394 & 2.814 & 3.629 & 2.438 & 2.915 & 3.830 & 2.558 & 3.107 & 3.797 \\
2.0 & 2.428 & 2.907 & 3.733 & 2.634 & 3.120 & 3.991 & 2.721 & 3.239 & 4.325 & 2.835 & 3.444 & 4.197 \\
\hline
\end{tabular}
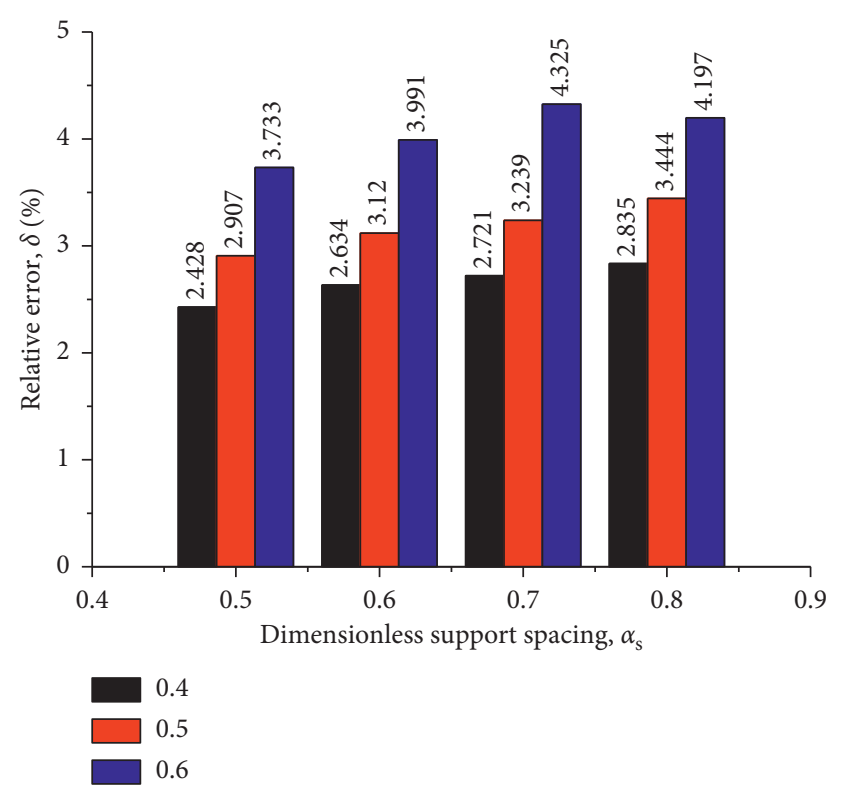

Figure 6: Maximum relative error of the dimensionless stress intensity factor for NSCB specimens.

in the range of the support spacing of $0.5 \sim 0.8$. Therefore, a curved surface formula is used to characterize their relationship. The fitted surface formula is shown in the following formula:

$$
Y=k_{0}+k_{1} \alpha_{2 b}+k_{2} \alpha_{0}+k_{3} \alpha_{2 b}^{2}+k_{4} \alpha_{0}^{2}+k_{5} \alpha_{2 b} \alpha_{0}
$$

where $k_{0} \sim k_{5}$ are parameters that represent a curved surface, which is related to the support spacing, $Y$ represents the dimensionless stress intensity factor, and $\alpha_{2 b}$ and $\alpha_{0}$ represent the dimensionless length and dimensionless width of the crack, respectively. The values of the parameters in formula (6) and the correlation of the surface formulas for different support spacing are shown in Table 3.

When the support spacing ranges from 0.5 to 0.8 , the correlation between the fitted surface by formula (6) and the data exceeds 0.99, which indicates that Formula (6) adequately reflects the relationship between the dimensionless stress intensity factor and the dimensionless length and width of the crack. After the preparation of the NSCB specimen, only the length and width of the prefabricated crack should be measured and appropriate parameter values for the formula should be selected according to the support spacing selected during the loading of the specimen to consider the influence of crack width and calculate the corresponding dimensionless stress intensity factor. This method eliminates the influence of the width of a prefabricated crack on the dimensionless stress intensity factor.

In theory, accurate rock fracture toughness test values can be obtained by the correction calculation of Formula (6) within the investigated range of the prefabricated crack size. However, the NSCB specimens of different sizes and widths of the prefabricated cracks have dimension effects and specimen heterogeneity effects during testing.

\section{Discussion}

Fracture toughness is one of the most important parameters in fracture mechanics. Accurate measurement of fracture toughness is of great significance for safety protection of engineering structures. The test results of fracture toughness are affected not only by the precision of test equipment, sample preparation, and human factors but also by the dimensionless stress intensity factor. Therefore, accurate calibration of dimensionless stress intensity factors of corresponding samples is a prerequisite for accurate measurement of fracture toughness.

Generally speaking, the research on dimensionless stress intensity factors mainly focuses on the geometry of the specimen, the length of the crack, and the angle between the crack plane and the load. However, when processing the specimen to test the fracture toughness, the prefabricated crack will inevitably have a certain width, which will make the stress distribution of blunt notched crack different from that of ideal zero width. Ayatollahi et al. [40] proposed an "effective Stretch Criterion" based on the existence of a damage zone around the crack tip and the dominant uniaxial nature of the stress field near the crack for fracture assessment of rubber-like materials weakened by a mode I crack. Berto and Ayatollahi [41] based on the local energy theory to assess the fracture properties of Brazil disk with blunt crack. Aliha et al. [42] 


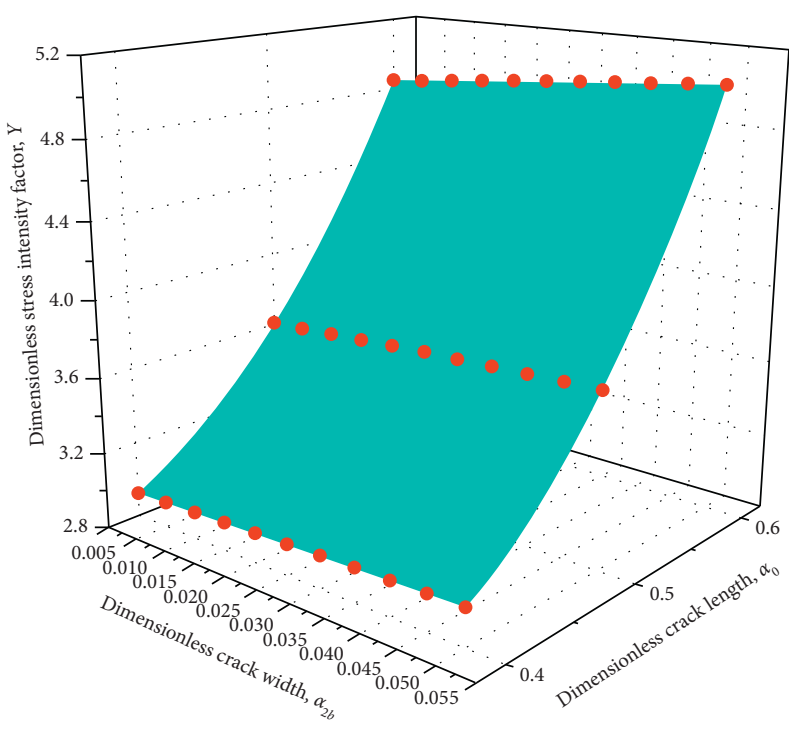

(a)

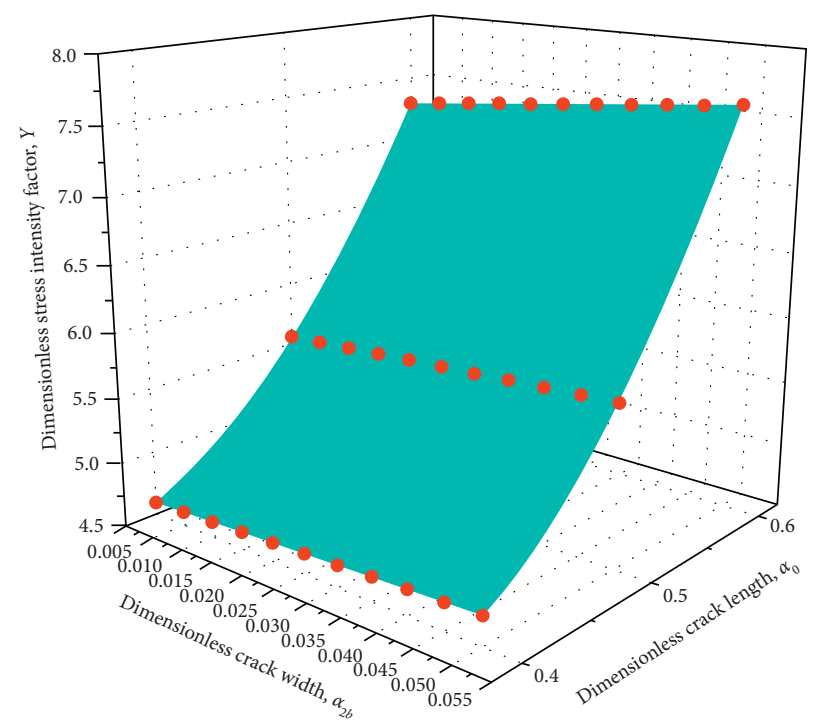

(c)

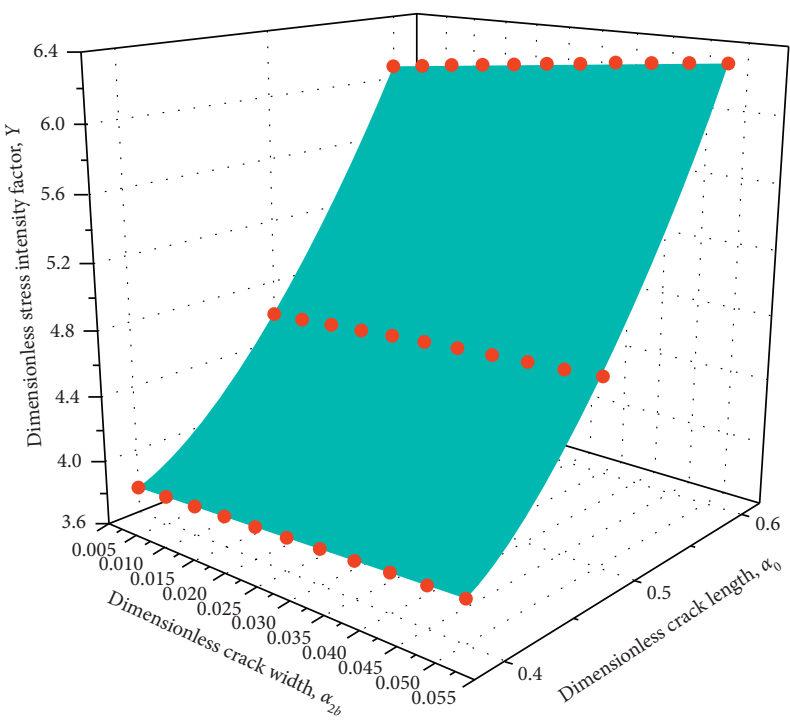

(b)

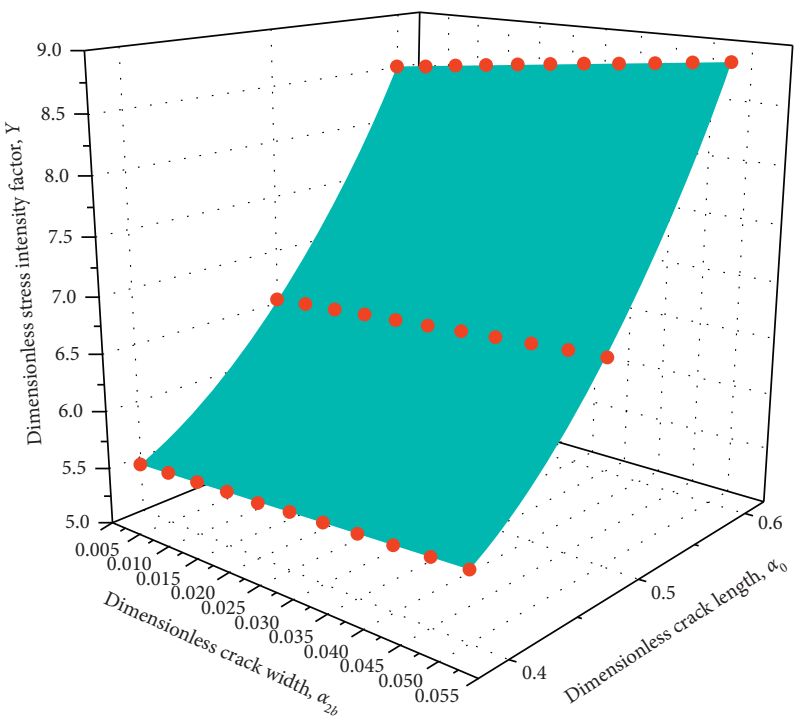

(d)

FiguRe 7: Fitting curves of the dimensionless crack width and the dimensionless stress intensity factor. (a) $\alpha_{\mathrm{S}}=0.5$, (b) $\alpha_{\mathrm{S}}=0.6$, (c) $\alpha_{\mathrm{S}}=0.7$, and (d) $\alpha_{\mathrm{S}}=0.8$.

TABLe 3: Value of parameters in formula (6).

\begin{tabular}{lcccccc}
\hline $\begin{array}{l}\text { Support } \\
\text { spacing }\end{array}$ & $k_{0}$ & $k_{1}$ & $k_{2}$ & $k_{3}$ & $k_{4}$ & $k_{5}$ \\
\hline$\alpha_{\mathrm{S}}=0.5$ & 5.9 & -2.776 & -18.806 & -7.413 & 28.427 & 11.109 \\
$\alpha_{\mathrm{S}}=0.6$ & 7.355 & -3.683 & -22.66 & -6.03 & 34.191 & 14.464 \\
$\alpha_{\mathrm{S}}=0.7$ & 8.814 & -5.088 & -26.525 & -1.74 & 39.977 & 18.582 \\
$\alpha_{\mathrm{S}}=0.8$ & 10.104 & -5.278 & -29.693 & -1.507 & 45.064 & 20.545 \\
\hline
\end{tabular}

successfully applied average strain energy density (ASED) criterion to composite fracture testing of rocks. On the other hand, an assumption of two-dimensional plane stress or plane strain delivers useful two-dimensional results with reasonable accuracy. However, threedimensional analysis is needed to fully understand the fracture process. Aliha and Saghafi [43] investigated the effects of thickness and Poisson's ratio on 3D mixed mode fracture. They found the stress intensity factor and T-stress results obtained from two-dimensional conditions, present lower estimate data for the real threedimensional cracked semi-circular bend specimen. Also, the influence of specimen thickness and Poisson's ratio is more pronounced for dominantly mode I condition in the semi-circular bend specimen. Berto et al. [44] made a review of corner point singularities under in-plane and out-of-plane loading. What is more, in the literature [13], Aliha et al. calibrated the dimensionless stress intensity factor (SIF) of the ENDB specimen comprehensively. In the next research step, the stress intensity factor of the three-dimensional U-shaped crack under mixed mode loading can be studied. 


\section{Conclusions}

The influence of the width of a prefabricated crack on the dimensionless stress intensity factor of NSCB specimens was analyzed using ABAQUS numerical software. The following main conclusions are obtained:

(1) As the width of the prefabricated crack increases, the dimensionless stress intensity factor of the NSCB specimen continuously increases. The longer is the length of the prefabricated crack, the "faster" is the increase in speed. The dimensionless support spacing has a minimal effect on the speed of change in the dimensionless stress intensity factor as the width of the prefabricated crack increases.

(2) Based on the dimensionless stress intensity factor obtained by calibration using the ideal crack, the errors in the dimensionless stress intensity factor caused by different widths of the prefabricated cracks are obtained when the widths are less than or equal to $2.0 \mathrm{~mm}$. When the support spacing is $\alpha_{\mathrm{S}}=0.7$ and the length of the prefabricated crack is $\alpha_{0}=0.6$, the maximum relative error is $4.325 \%$. Therefore, the influence of the artificial width of the prefabricated crack on the dimensionless stress intensity factor cannot be disregarded.

(3) The corrected formula that considers the influence of the width of a prefabricated crack on the dimensionless strength factor is given for any dimensionless support spacing in the range of $0.5 \sim 0.8$. The degree of fit using the formula exceeds 0.99. Using this formula and the specimen fracture load and geometric parameters, the fracture toughness test value of an NSCB specimen considering the influence of the width of a prefabricated crack can be obtained.

\section{Nomenclature}

$\begin{array}{ll}a: & \text { Crack length } \\ b: & \text { Half of crack width } \\ B: & \text { Thickness of specimen } \\ E: & \text { Elastic modulus } \\ J: & \text { J-integral } \\ K_{\mathrm{I}}: & \text { Mode I stress intensity factor } \\ k_{0} \sim k_{5}: & \text { Fitting constants related to formula }(6) \\ P: & \text { Concentrated load } \\ P_{\text {max }}: & \text { Crack initiation load } \\ R: & \text { Radius of specimen } \\ S: & \text { Support spacing } \\ \mu: & \text { Poisson's ratio } \\ Y: & \text { Dimensionless stress intensity factor } \\ Y_{0}: & \text { Dimensionless stress intensity factor of the } \\ Y_{2 b}: & \text { 0 mm-width crack } \\ \alpha_{0}: & \text { Dimensionless stress intensity factor of the } \\ \alpha_{2 b}: & \text { Dimensionless crack length }\end{array}$

$\alpha_{\mathrm{t}}: \quad$ Dimensionless specimen thickness

$\alpha_{\mathrm{s}}: \quad$ Dimensionless support spacing

$\delta: \quad$ Relative error

CB: Chevron notched three-point bend round bar specimen

CCNBD: Cracked chevron notched Brazilian disc specimen

CPS6: 6-node triangular plane stress element

CPS8: $\quad$ 8-node quadrilateral element

CSTFBD: Cracked straight-through flattened Brazilian disk

DCR: Diametrally compressed ring

ECT: $\quad$ Edge cracked triangular

ENDB: Edge-notched disc bend

HCFBD: Holed-cracked flattened Brazilian disc specimen

ISRM: International Society for Rock Mechanics

SR: Chevron notched short rod specimen

TCD: Theory of critical distances.

\section{Data Availability}

The data supporting this research article are available from the corresponding author via e-mail.

\section{Conflicts of Interest}

The authors declare that they have no conflicts of interest.

\section{Acknowledgments}

This study was financially supported by the National Key Research and Development Program of China (Grant no. 2016YFC0600701), the National Natural Science Foundation of China (Grant nos. 51674101, 51674170, and 51822403), and the Key Laboratory Open Project Fund in Henan Province (Grant no. S201605). The authors express their gratitude for the supportive help and instructions of the managers.

\section{References}

[1] W. S. Kreher, "Influence of domain switching zones on the fracture toughness of ferroelectrics," Journal of the Mechanics and Physics of Solids, vol. 50, no. 5, pp. 1029-1050, 2002.

[2] M. Enderlein, A. Ricoeur, and M. Kuna, "Finite element techniques for dynamic crack analysis in piezoelectrics," International Journal of Fracture, vol. 134, no. 3-4, pp. 191-208, 2005.

[3] M. R. M. Aliha, M. R. Ayatollahi, D. J. Smith, and M. J. Pavier, "Geometry and size effects on fracture trajectory in a limestone rock under mixed mode loading," Engineering Fracture Mechanics, vol. 77, no. 11, pp. 2200-2212, 2010.

[4] M. R. M. Aliha and M. R. Ayatollahi, "Rock fracture toughness study using cracked chevron notched Brazilian disc specimen under pure modes I and II loading-a statistical approach," Theoretical and Applied Fracture Mechanics, vol. 69, pp. 1725, 2014.

[5] M. R. M. Aliha, E. Mahdavi, and M. R. Ayatollahi, "The influence of specimen type on tensile fracture toughness of rock materials," Pure and Applied Geophysics, vol. 174, no. 3, pp. 1237-1253, 2017. 
[6] F. Ouchterlony, "Suggested methods for determining the fracture toughness of rock," International Journal of Rock Mechanics and Mining Sciences \& Geomechanics Abstracts, vol. 25, no. 2, pp. 71-96, 1988.

[7] R. J. Fowell, "Suggested method for determining mode I fracture toughness using Cracked Chevron Notched Brazilian Disc (CCNBD) specimens," International Journal of Rock Mechanics and Mining Sciences \& Geomechanics Abstracts, vol. 32, no. 1, pp. 57-64, 1995.

[8] M. D. Kuruppu, Y. Obara, M. R. Ayatollahi, K. P. Chong, and T. Funatsu, "ISRM-Suggested method for determining the mode I static fracture toughness using semi-circular bend specimen," Rock Mechanics and Rock Engineering, vol. 47, no. 1, pp. 267-274, 2014.

[9] M. R. M. Aliha, M. R. Ayatollahi, and R. Pakzad, "Brittle fracture analysis using a ring-shape specimen containing two angled cracks," International Journal of Fracture, vol. 153, no. 1, pp. 63-68, 2008.

[10] M. R. M. Aliha, R. Pakzad, and M. R. Ayatollahi, "Numerical analyses of a cracked straight-through flattened Brazilian disk specimen under mixed-mode loading," Journal of Engineering Mechanics, vol. 140, no. 1, pp. 219-224, 2014.

[11] M. R. M. Aliha, G. R. Hosseinpour, and M. R. Ayatollahi, "Application of cracked triangular specimen subjected to three-point bending for investigating fracture behavior of rock materials," Rock Mechanics and Rock Engineering, vol. 46, no. 5, pp. 1023-1034, 2013.

[12] M. R. M. Aliha, A. Bahmani, and S. Akhondi, "Determination of mode III fracture toughness for different materials using a new designed test configuration," Materials \& Design, vol. 86, no. 5, pp. 863-871, 2015.

[13] M. R. M. Aliha, A. Bahmani, and S. Akhondi, "Numerical analysis of a new mixed mode I/III fracture test specimen," Engineering Fracture Mechanics, vol. 134, pp. 95-110, 2015.

[14] M. R. M. Aliha and A. Bahmani, "Rock fracture toughness study under mixed mode I/III loading," Rock Mechanics and Rock Engineering, vol. 50, no. 7, pp. 1739-1751, 2017.

[15] K. P. Chong and M. D. Kuruppu, "New specimen for fracture toughness determination for rock and other materials," International Journal of Fracture, vol. 26, no. 2, pp. 59-62, 1984.

[16] M. R. Ayatollahi and M. R. M. Aliha, "Fracture toughness study for a brittle rock subjected to mixed mode I/II loading," International Journal of Rock Mechanics and Mining Sciences, vol. 44, no. 4, pp. 617-624, 2007.

[17] M. R. M. Aliha, M. R. Ayatollahi, and J. Akbardoost, "Typical upper bound-lower bound mixed mode fracture resistance envelopes for rock material," Rock mechanics and Rock engineering, vol. 45, no. 1, pp. 65-74, 2012.

[18] M. R. M. Aliha, M. Heidari-Rarani, M. M. Shokrieh, M. R. Ayatollahi, and M. R. Ayatollahi, "Experimental determination of tensile strength and $\mathrm{K}(\mathrm{IC})$ of polymer concretes using semi-circular bend (SCB) specimens," Structural Engineering and Mechanics, vol. 43, no. 6, pp. 823-833, 2012.

[19] M. R. M. Aliha, M. Sistaninia, D. J. Smith, M. J. Pavier, and M. R. Ayatollahi, "Geometry effects and statistical analysis of mode I fracture in guiting limestone," International Journal of Rock Mechanics and Mining Sciences, vol. 51, pp. 128-135, 2012.

[20] M. R. M. Aliha and M. R. Ayatollahi, "Two-parameter fracture analysis of SCB rock specimen under mixed mode loading," Engineering Fracture Mechanics, vol. 103, pp. 115-123, 2013.

[21] J. Akbardoost, M. R. Ayatollahi, M. R. M. Aliha, M. J. Pavier, and D. J. Smith, "Size-dependent fracture behavior of Guiting limestone under mixed mode loading," International Journal of Rock Mechanics and Mining Sciences, vol. 71, pp. 369-380, 2014.

[22] M. Fakhri, E. Amoosoltani, and M. R. M. Aliha, "Crack behavior analysis of roller compacted concrete mixtures containing reclaimed asphalt pavement and crumb rubber," Engineering Fracture Mechanics, vol. 180, pp. 43-59, 2017.

[23] M. M. Mirsayar, X. Shi, and D. G. Zollinger, "Evaluation of interfacial bond strength between Portland cement concrete and asphalt concrete layers using bi-material SCB test specimen," Engineering Solid Mechanics, vol. 5, no. 4, pp. 293-306, 2017.

[24] A. S. Fayed, "Numerical evaluation of mode I/II SIF of quasibrittle materials using cracked semi-circular bend specimen," Engineering Solid Mechanics, vol. 6, no. 2, pp. 175-186, 2018.

[25] Z. M. Zhu and H. S. Wang, "Effect of notch root radius on rock fracture toughness $K_{\mathrm{Ic}}$," Journal of Experimental Mechanics, vol. 8, no. 1, pp. 92-95, 1993.

[26] F. Dai and Q. Z. Wang, "Effects of finite notch width on stress intensity factor for CCNBD specimen," Rock and Soil Mechanics, vol. 3, no. 5, pp. 427-431, 2004.

[27] S. M. Dong, M. Y. Fang, and Y. M. Xia, "Effect of crack shape and size on stress intensity factors of central cracked circular disk," Journal of University of Science and Technology of China, vol. 34, no. 4, pp. 449-455, 2004.

[28] G. Q. Zhang, M. Chen, and X. Y. Yang, "Influence of fracture width on rock toughness measurement," Journal of the University of Petroleum China (Edition of Natural Science), vol. 26, no. 6, pp. 42-45, 2002.

[29] S. Zhang and Y. L. Liang, "Influence of prefabricated crack width on determining rock fracture toughness for holecracked flattened Brazilian disc," Journal of Experimental Mechanics, vol. 28, no. 4, pp. 517-523, 2013.

[30] J. Zhou, Y. Wang, S. M. Dong, and Y. M. Xia, "Effect of specimen geometry on mode I fracture toughness of PMMA," Polymer Material Science and Engineering, vol. 21, no. 6, pp. 11-14, 2005.

[31] Z. L. Cui, N. P. Gong, and L. W. Jing, "Experiment and finite element analysis of rock dynamic fracture toughness test on non ideal crack disc specimens," Rock and Soil Mechanics, vol. 36, no. 3, pp. 694-702, 2015.

[32] Q. Z. Wang, D. B. Yan, and L. Luo, "Stress concentration factors for beams with single side U-shaped notched subjected to pure bending and a new method for mechanical test of quasi-brittle materials," Science Technology and Engineering, vol. 8, no. 12, pp. 3096-3102, 2008.

[33] L. Luo and Q. Z. Wang, "Concurrent measurement of tensile strength and fracture toughness of quasi-brittle materials using U-notched beams: theoretical analysis," Engineering Mechanics, vol. 26, no. 9, pp. 244-250, 2009.

[34] L. Luo, J. R. Yang, and Q. Z. Wang, "Concurrent measurement of tensile strength and fracture toughness of quasi-brittle materials using U-notched beams: experimental analysis," Journal of Basic Science and Engineering, vol. 25, no. 1, pp. 89-101, 2017.

[35] R. Kolhe, C.-Y. Hui, and A. T. Zehnder, "Effects of finite notch width on the fracture of chevron-notched specimens"," International Journal of Fracture, vol. 94, no. 2, pp. 189-198, 1998.

[36] E. Barati and Y. Alizadeh, "A notch root radius to attain minimum fracture loads in plates weakened by U-notches under mode I loading," Scientia Iranica, vol. 19, no. 3, pp. 491-502, 2012. 
[37] S. Cicero, V. Madrazo, and I. A. Carrascal, "Analysis of notch effect in PMMA using the theory of critical distances," Engineering Fracture Mechanics, vol. 86, pp. 56-72, 2012.

[38] M. Dehghany, H. Saeidi Googarchin, and M. R. M. Aliha, "The role of first non-singular stress terms in mixed mode brittle fracture of V-notched components: an experimental study," Fatigue \& Fracture of Engineering Materials \& Structures, vol. 40, no. 4, pp. 623-641, 2017.

[39] M. K. Hussain and K. S. R. K. Murthy, "A point substitution displacement technique for estimation of elastic notch stress intensities of sharp V-notched bodies," Theoretical and Applied Fracture Mechanics, vol. 97, pp. 87-97, 2018.

[40] M. R. Ayatollahi, M. Heydari-meybodi, M. Dehghany, and F. Berto, "A new criterion for rupture assessment of rubberlike materials under mode-I crack loading: the effective stretch criterion," Advanced Engineering Materials, vol. 18, no. 8, pp. 1364-1370, 2016.

[41] F. Berto and M. R. Ayatollahi, "Fracture assessment of Brazilian disc specimens weakened by blunt V-notches under mixed mode loading by means of local energy," Materials \& Design, vol. 32, no. 5, pp. 2858-2869, 2011.

[42] M. R. M. Aliha, F. Berto, A. Mousavi, and S. M. J. Razavi, "On the applicability of ASED criterion for predicting mixed mode I + II fracture toughness results of a rock material," Theoretical and Applied Fracture Mechanics, vol. 92, pp. 198-204, 2017.

[43] M. R. M. Aliha and H. Saghafi, "The effects of thickness and Poisson's ratio on 3D mixed-mode fracture," Engineering Fracture Mechanics, vol. 98, pp. 15-28, 2013.

[44] F. Berto, L. P. Pook, and A. Campagnolo, "Corner point singularities under in-plane and out-of-plane loading: a review of recent results," Engineering Solid Mechanics, vol. 5, no. 3, pp. 167-176, 2017. 


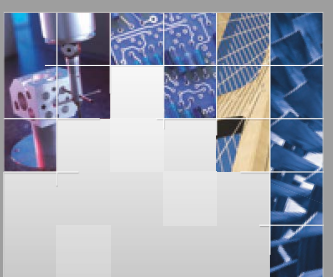

\section{Enfincering}
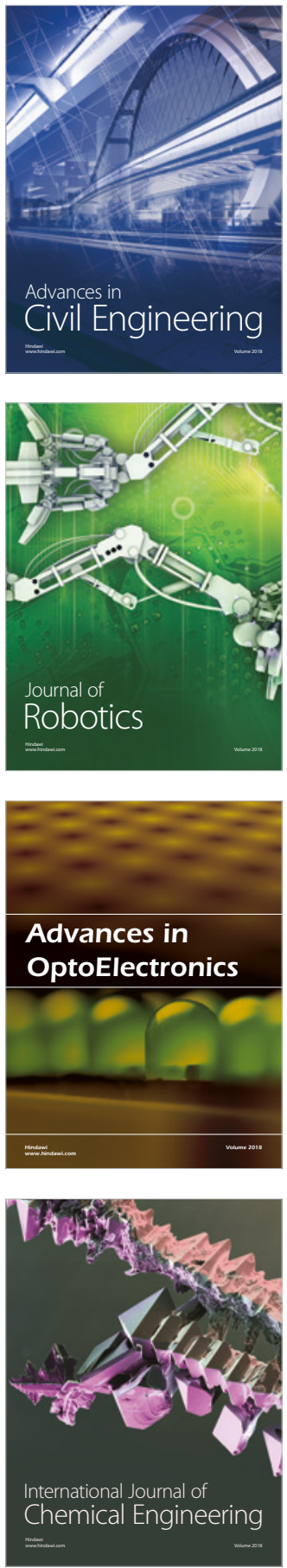

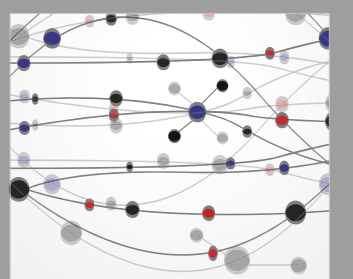

\section{Rotating \\ Machinery}

The Scientific World Journal

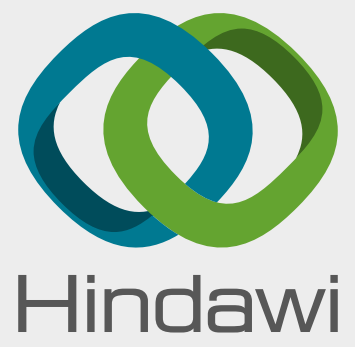

Submit your manuscripts at

www.hindawi.com
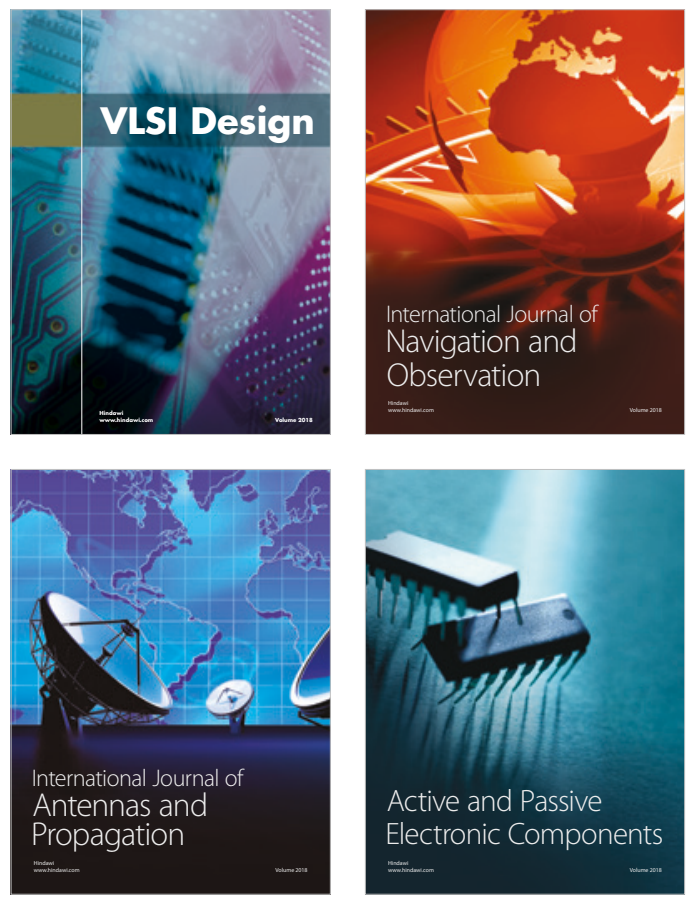
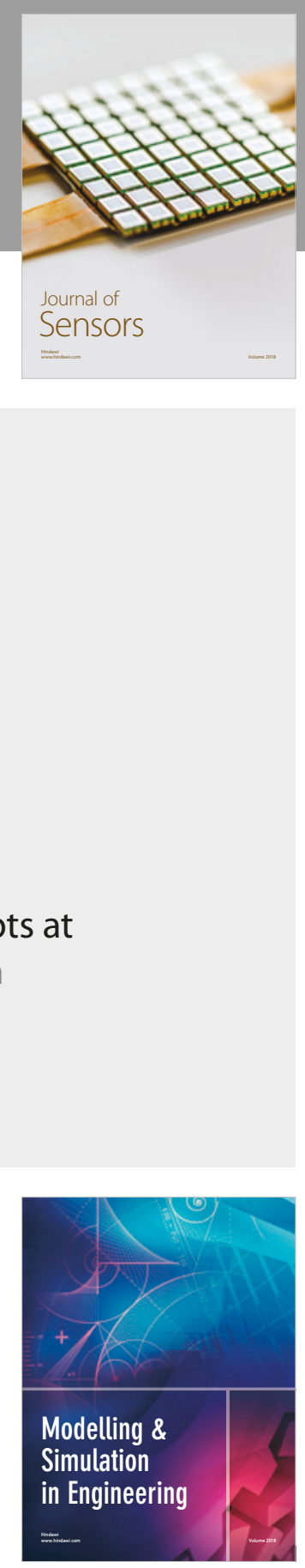

\section{Advances \\ Multimedia}
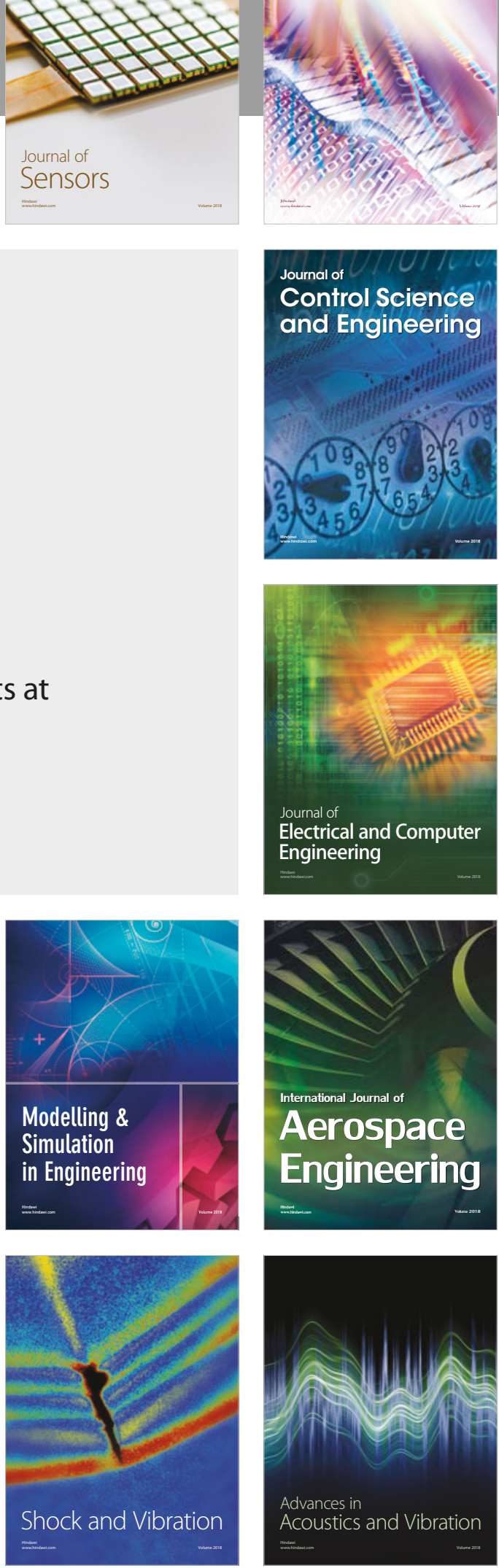